\title{
Correlation between Iron Reducibility in Natural and Iron-Modified Clays and Its Adsorptive Capability for Arsenic Removal
}

\author{
Irma Lia Botto', Simonetta Tuti², María Jose Gonzalez ${ }^{1,3}$, Delia Gazzoli ${ }^{4}$ \\ ${ }^{1}$ CEQUINOR (CCT-La Plata-UNLP), La Plata, Argentina \\ ${ }^{2}$ Dipartimento di Scienze, Universitá Roma Tre, Roma, Italy \\ ${ }^{3}$ INREMI (CICPBA-UNLP), La Plata, Argentina \\ ${ }^{4}$ Dipartimento di Chimica, Universitá La Sapienza, Roma, Italy \\ Email: botto@quimica.unlp.edu.ar
}

Received 2 March 2016; accepted 27 May 2016; published 30 May 2016

Copyright (C) 2016 by authors and Scientific Research Publishing Inc.

This work is licensed under the Creative Commons Attribution International License (CC BY). http://creativecommons.org/licenses/by/4.0/

(c) (i) Open Access

\begin{abstract}
The study reports aspects that allowed to correlate structural and redox properties of iron species deposited on clay minerals with the capacity of geomaterials for arsenic removal. Natural ferruginous clays as well as an iron-poor clay chemically modified with Fe(III) salt (ferrihydrite species) were investigated as adsorbents of the arsenate(V) in water. The study, carried out from minerals from abundant Argentinean deposits, was conducted with the aid of different techniques such as X-ray Diffraction (XRD), Scanning Electron Microscopy (SEM-EDS), Raman Spectroscopy, ICP-AES (Inductively Coupled Plasma) chemical analysis and Temperature Programmed Reduction (TPR). This last technique allowed to detect availability of iron species in oxidic environment with different structural complexity and to determine active sites, accessible for arsenate(V) adsorption. The effect was observed through temperature dependence of the first Fe(III) reduction step (below $570^{\circ} \mathrm{C}$ ) of iron-oxide species. The sequence of reducibility: ferrihydrite > hydrous oxide (goethite) > anhydrous oxide (hematite) $>$ structural iron in clay was in agreement with the availability of iron active sites for the reducing process as well as for the arsenate adsorption. The important role of very high iron content in original samples was also observed. The chemical activation of iron-poor clay by a simple and feasible modification with Fe(III) solutions promoted the deposition of the ferrihydrite active phase with an increase of $2.81 \%$ (expressed as $\mathrm{Fe}_{2} \mathrm{O}_{3}$ ) respect to the original content of $1.07 \%$, constituting an accessible and eco-friendly technological alternative to solve the environmental problem of water containing arsenic.
\end{abstract}

\section{Keywords}

Temperature Programmed Reduction, Iron-Oxide Species, Arsenic Removal 


\section{Introduction}

A series of innovative and alternative technologies have been developed in last years for dealing different type of environmental problems in worldwide. Among others, the presence of arsenic in groundwater, usual source of drinking water for a great number of people in the world, has received significant attention particularly due to the high toxicity of the As(III and V) inorganic forms. Occurrence of As in natural water is associated with local geology and particularly with the geochemical aspects of host aquifer materials which control the mobility of the contaminant [1]-[4].

The most As removal methods are expensive, so, new or modified treatments are in permanent development, specially to solve the problem in rural areas or in vulnerable populations where the drinkable water is not available. Research efforts are done to establish a simple, inexpensive and locally appropriate method to arrive to the $10 \mathrm{ppb}$ As background, recommended by the WHO. With this aim the effectiveness of arsenic removal capacity by means of natural $\mathrm{Al}, \mathrm{Mn}$ and Fe oxide phases was extensively studied, related to the geochemical affinity between arsenate(V) oxoanion and metallic oxide species [5]-[11]. In this sense, iron oxy-hydroxides as goethite, hematite and red mud as well as ferruginous clay minerals are used as adsorbents with different results [7] [8] [10].

On the other hand, it is well known, that either in geochemical processes or in laboratory experiments, the hydrolysis of ferric ions leads to the formation of Fe-O or Fe-O-H species, covering the surface of mineral particles. Nanoparticles of ferric oxy-hydroxide phases increase the surface area and provide the active sites to attract arsenate ions [12]. More specifically, ferrihydrite $\left(\mathrm{Fe}_{10} \mathrm{O}_{14}(\mathrm{OH})_{2}\right)$, is characterized by a high specific surface area $\left(250-500 \mathrm{~m}^{2} \cdot \mathrm{g}^{-1}\right)$ and this property is usually accomplished by a high reactivity, influencing geochemical reactions such as retention of aqueous contaminants [13]. Ferrihydrite is also a metastable phase, transforming slowly to crystalline hematite, the usual alteration product [14]. Likewise, the low crystallinity and the distorted geometry of iron environment are the key for the adsorption mechanism of species. In this sense, the Fe-coated materials are considered as a viable low-cost system to be used for the contaminant removal in poor Asian countries [12] [15] [16].

Natural aluminosilicates, particularly clays, are available and low cost mineral species, which act as sorbents to remove heavy metals and other type of ionic contaminants from the aqueous medium. The adsorption capacity of clays is associated to the lamellar structure and its negative charge; need to adsorb cationic species and oxide metallic clusters [17].

In order to get profit from the abundance and availability of natural clays from Argentinean deposits, a series of these mineral species has been selected to be analyzed in the sorption process, either in natural form or chemically modified (from the treatment of iron poor clays with iron solutions). So, chemical characterization of Fe-rich clay minerals as well as iron modified clays was carried out to evaluate the operating performance of these materials in the As removal [18] [19]. Hence, physical and chemical properties of iron species, from crystalline to colloidal forms and from simple to complex structural systems, play a decisive role in the interaction ability useful for the adsorptive process. On the basis of these features, the TPR technique seems to be an interesting tool to analyze the iron reactivity in these systems which could be related to the availability of active sites for the interaction with arsenate. The aim of this work, carried out by using original minerals as well as a modified aluminosilicate system, was to evaluate the capability of iron active sites to adsorb arsenate species remarking aspects that can be interesting in the development of As removal technologies. X-ray diffraction (XRD), scanning electron microscopy (SEM-EDS), Raman spectroscopy as well as chemical analysis by inductively coupled plasma for major elements (ICP-AES), can contribute to interpret the temperature programmed reduction (TPR) behavior.

\section{Materials and Methods}

\subsection{Materials}

The study was done by using natural 1:1 and 2:1 lamellar materials from clay Argentinean deposits. Five natural samples (particle size lower than $10 \mu \mathrm{m}$ ) with different iron content, identified as C1 to C5, were selected for this study.

The sample with the lowest iron content was chosen to modify chemically. It was named MC5, where C5 is the original identification. Chemical modification to increase the iron content was carried out according to the 
Schwertman and Cornell technique [20]. To obtain nanoscopic ferrihydrite (Fy), $20 \mathrm{~g}$ of Fe( $\left(\mathrm{NO}_{3}\right)_{3} \cdot 9 \mathrm{H}_{2} \mathrm{O}(\mathrm{Al}-$ drich) were dissolved in $250 \mathrm{~mL}$ of water. The solution was added to $100 \mathrm{~g}$ of the aluminosilicate. Then, a solution of $155 \mathrm{~mL}$ of $\mathrm{NaOH} 1 \mathrm{M}$ was incorporated in a magnetic mixer. The final $\mathrm{pH}$ was adjusted by dropping of alkaline solution to reach $\mathrm{pH}$ 7. The mixture was centrifuged during $10 \mathrm{~min}(2000 \mathrm{rpm})$, washed with water to negative reaction of nitrate and the solid was dried at $60^{\circ} \mathrm{C}$.

\subsection{Characterization}

Chemical analyses of the bulk (in original and modified forms) were done by the ICP-AES technique for major elements. Arsenic content was determined by ICP-MS (Lab, Als Chemex Canada). X-ray diffraction data were registered in a Phillips PW 3710 diffractometer, $\mathrm{CuK} \alpha$-Ni filtered radiation. SEM morphological measurements were carried out in a Phillips 505 electron microscope, with an EDS-EDAX instrument to reveal the surface chemical content. ASAP 2020 Micromeritics Physisorption Analyzer was employed to make BET measures. Degasification of samples was performed for $10 \mathrm{~h}$ at $\mathrm{P}<10 \mu \mathrm{m}$ of $\mathrm{Hg}$ and $100^{\circ} \mathrm{C}$. Specific surface area was determined from $\mathrm{N}_{2}$ adsorption isotherm in the pressure range $\left(\mathrm{P} / \mathrm{P}_{0}\right) 0.01-0.3$.

Raman spectroscopic studies were carried out on exhausted samples by means of inVia Renishaw micro-Raman spectrometer, equipped with an air-cooled CCD detector and edge filters. A $488.0 \mathrm{~nm}$ emission line from an $\mathrm{Ar}$ ion laser was focused on the sample by a Leica DLML microscope, using $5 \times$ or $20 \times$ objectives. The power of the incident beam is about $5 \mathrm{~mW}$. Five $10 \mathrm{~s}$ accumulations were generally acquired for each sample. The resolution was $2 \mathrm{~cm}^{-1}$ and spectra were calibrated using the $520.5 \mathrm{~cm}^{-1}$ line of a silicon wafer. Data analysis included baseline removal and curve fitting, using a Gauss-Lorentz cross-product function by Peakfit 4.12 software (Jandel, AISN Software).

TPR experiments were performed in a flow apparatus Thermo Scientific TPDRO 1100. The $\mathrm{H}_{2}$ consumption was detected by a TCD detector, calibrated by the reduction of a known amount of $\mathrm{CuO}(99.99 \%$ purity from Sigma Aldrich). Samples were reduced in a flow of $5 \% \mathrm{H}_{2} / \mathrm{Ar}$ mixture $\left(10 \mathrm{~cm}^{3} \mathrm{STP}^{\cdot} \cdot \mathrm{min}^{-1}\right)$ in the RT- $900^{\circ} \mathrm{C}$ range, with a ramp of $10^{\circ} \mathrm{C} \cdot \mathrm{min}^{-1}$. Before flowing into the TCD detector, the $\mathrm{H}_{2} \mathrm{O}$ generated in the reduction was removed by a trap. The iron reduction degree was evaluated from $\mathrm{H}_{2}$ consumption and reported as electron exchanged per iron atom $\mathrm{e}^{-} / \mathrm{Fe}=2\left(\mathrm{H}_{2} \mathrm{~mol} / \mathrm{Fe} \mathrm{mol}\right)$. TPO experiments were performed with a $5 \% \mathrm{O}_{2} / \mathrm{He}$ mixture $\left(10 \mathrm{~cm}^{3} \mathrm{STP}^{-} \mathrm{min}^{-1}\right)$ starting from RT and heating up to $800^{\circ} \mathrm{C}$, with a ramp of $20^{\circ} \mathrm{C} \cdot \mathrm{min}^{-1}$.

\subsection{Arsenic Adsorption Tests}

Batch experiments for adsorbing As on mineral samples were carried out on the basis of a previously reported procedure [18]. The adsorbent/water ratio $=1 / 10, \mathrm{pH} 7$, As solution containing $1000 \mu \mathrm{g} \cdot \mathrm{L}^{-1}$ and room temperature $\left(20^{\circ} \mathrm{C} \pm 2{ }^{\circ} \mathrm{C}\right)$ were employed by means a Jar test equipment (Velp). The slurry was stirred during 60 min at $200 \mathrm{rpm}$ to reach an optimal contact. The suspended solid was decanted for $24 \mathrm{~h}$ with the aid of a small amount of APC (aluminum polychloride) (0.193 mg Al per liter of contaminated water). Material effectiveness was established through the amount of As adsorbed (As $\mu$ g for gram of mineral) as a function of the number of consecutive treatments up to saturation of the adsorbent (concentration of arsenic in the solution exceeding 10 $\mu \mathrm{g} \cdot \mathrm{L}^{-1}$ ). The As in solution was analyzed by a Perkin Elmer Analyst 200 (equipped with a Perkin Elmer HGA 900 Graphite-Furnace).

\section{Results and Discussion}

Table 1 gives ICP-AES chemical analyses of major elements for samples, expressed as $\mathrm{w} / \mathrm{w} \%$ oxides. The iron content (expressed as $\mathrm{Fe}_{2} \mathrm{O}_{3}$ ) ranged between $1.07 \%$ and $54.50 \%$ for natural clays, whereas for the iron modified sample (MC5) the iron was increased from $1.07 \%$ (C5) to $3.88 \%$. The $\mathrm{SiO}_{2} / \mathrm{Al}_{2} \mathrm{O}_{3}$ ratio remained practically constant or slightly increased (3.75 and 3.90 for C5 and MC5 respectively) as observed in activated aluminosilicates [18] [19] [21]. Natural arsenic contents (expressed as ppm of element) were ranged between 3.0 (Fepoorest clay) to $29.1 \mathrm{ppm}$ (Fe-richest clay).

Figure 1 shows the XRD patterns of $\mathrm{C} 1$ to $\mathrm{C} 4$ clays. The dominance of 1:1 clay structure of kaolinite (PDF 89-6538) was observed in the C1 pattern. However, weak diffraction lines of illite (PDF 26-0911) and the main X-ray signals of goethite (PDF 29-0713) were also observed. Samples C2 and C3 were characterized by illite presence as major phase. X-ray diffraction lines of goethite and hematite (PDF 88-2359) can be observed in C2 
Table 1. ICP-AES chemical analyses of studied samples.

\begin{tabular}{|c|c|c|c|c|c|c|}
\hline Oxide \% & $\mathrm{C} 1$ & $\mathrm{C} 2$ & C3 & $\mathrm{C} 4$ & C5 & MC5 \\
\hline $\mathrm{SiO}_{2}$ & 47.24 & 52.66 & 61.50 & 21.24 & 69.81 & 68.41 \\
\hline $\mathrm{Al}_{2} \mathrm{O}_{3}$ & 26.20 & 18.05 & 18.59 & 15.66 & 18.62 & 17.53 \\
\hline $\mathrm{Fe}_{2} \mathrm{O}_{3}$ & 7.39 & 13.80 & 9.00 & 54.50 & 1.07 & 3.88 \\
\hline $\mathrm{CaO}$ & 0.75 & 0.48 & 0.15 & 0.22 & 0.75 & 0.51 \\
\hline $\mathrm{MgO}$ & 0.98 & 1.64 & 0.64 & 0.13 & 0.39 & 0.32 \\
\hline $\mathrm{Na}_{2} \mathrm{O}$ & 0.09 & 0.09 & 0.56 & 0.23 & 0.18 & 0.16 \\
\hline $\mathrm{K}_{2} \mathrm{O}$ & 1.01 & 4.72 & 4.56 & 1.40 & 4.42 & 4.56 \\
\hline $\mathrm{TiO}_{2}$ & 0.77 & 0.92 & 1.04 & 0.61 & 1.05 & 0.87 \\
\hline $\mathrm{MnO}$ & 0.02 & 0.07 & 0.01 & 0.13 & 0.01 & 0.01 \\
\hline $\mathrm{P}_{2} \mathrm{O}_{5}$ & 0.15 & 0.14 & 0.01 & 0.29 & 0.04 & 0.04 \\
\hline LOI & 15.40 & 7.43 & 3.94 & 5.60 & 3.66 & 3.71 \\
\hline As ppm & 20.0 & 25.1 & 23.0 & 29.1 & 3.0 & n.d. \\
\hline
\end{tabular}

n.d.: not determined.

sample, whereas hematite was predominant phase in C3 sample, although a small signal of goethite can be suggested. The diffraction pattern of C4 iron-rich clay showed the presence of pyrophyllite (PDF 46-1308) as dominant phase with small proportion of kaolinite, illite and hematite as associated species. No lines of other iron oxides were detected. All studied samples show a variable content of $\alpha$-quartz (PDF 89-8941), which appeared as associated phase.

C5 sample was dominated by the illite presence and quartz associated phase, as it is observed in Figure 2 (bottom). The pattern corresponding to the iron modified sample (MC5) is shown at the top of Figure 2. The comparison of both XRD patterns reveals that there are not mineralogical differences. This finding could be attributed to the small amount of added iron and/or to the low crystallinity of the deposited iron phase. In this sense, the formation of iron oxides is affected by the presence of foreign species, which can avoid the transformation of ferrihydrite to crystalline phases [18].

SEM-EDS microscopy was useful to analyze morphological differences among samples and the semi-quantitative iron content. Figure 3 shows the morphology of $\mathrm{C} 1$ sample, typical of kaolinite, with iron-rich zones (up to $21 \% \mathrm{Fe}_{2} \mathrm{O}_{3}$ ). On the other hand, Figure 4 shows the morphology of the natural Fe-rich clay (C4 sample). In this case, the iron surface value reaches up to $68 \% \mathrm{Fe}_{2} \mathrm{O}_{3}$ with a heterogeneous distribution. The considerably higher content of iron at surface level can be attributed to geochemical processes of iron dissolution-deposition by $\mathrm{Fe}(\mathrm{III})$ hydrolysis leading to iron oxi-hydroxides and finally the stable hematite phase. Figure 5 allowed us to compare the increase of iron content in surface in C5 and MC5 systems, from 1.29\% to 5.04\% $\mathrm{Fe}_{2} \mathrm{O}_{3}$.

The BET specific surface area for the ferruginous samples is lower than $12.4 \mathrm{~m}^{2} \cdot \mathrm{g}^{-1}$, whereas the value for C5 is $4.97 \mathrm{~m}^{2} \cdot \mathrm{g}^{-1}$ increasing to $27.27 \mathrm{~m}^{2} \cdot \mathrm{g}^{-1}$ for the MC5 chemical modification. The ferrihydrite used as reference presented prevalence of mesopores (average pore width $28.47 \AA$ ) whereas C5 material presented a wide distribution of meso and macropores (average pore width $134.27 \AA$ ). The MC5 activated sample showed an intermediate behavior, with an increase of mesopores and a pronounced decrease of macropores (average pore width $49.83 \AA$ ). The increase of mesopores in the MC5 sample can be correlated to the higher specific surface introduced by effect of iron-nanophase deposition, partially covering the original macropores [11] [18] [19] [21].

Figure 6 (top) shows the typical micro-Raman spectra of iron oxide surface spots in the C4 sample. Spectra are characterized by bands close to 225, 300, 412, 500, 611 and $1321 \mathrm{~cm}^{-1}$, values in accordance with reported data for natural hematite [22] [23]. Raman spectrum of MC5 with the ferrihydrite phase coating clay particles was very difficult to obtain because it was rapidly transformed during Raman measurement due to laser power and exposure time (Figure 6 bottom). In this sense, Mazzetti et al. [24] report the effect of the repeated scans and a laser power higher than $1 \mathrm{~mW}$ on the sample, leading to the transformation to hematite phase.

Temperature Programmed Reduction is an interesting technique to analyze the reducibility of transition elements in oxide systems. In this context, reduction of hematite and other single and complex Fe-oxides were 


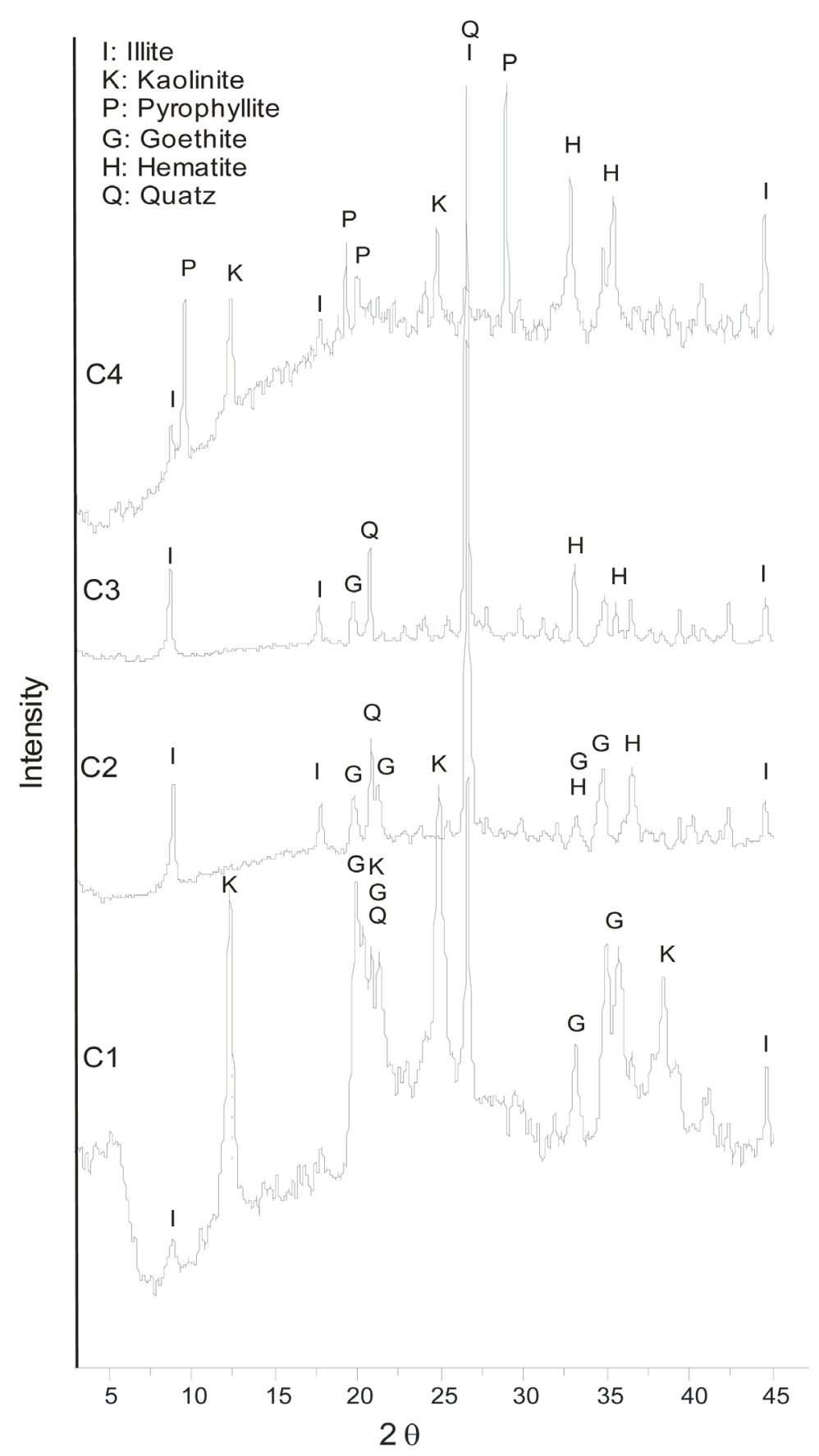

Figure 1. XRD patterns of C1, C2, C3 and C4 clay samples.

widely studied [25] [26]. In aluminosilicates, iron species appears as Fe(III) or Fe(II), depending on the structural lattice and they can be reduced only from the lattice collapse. It is well known, however, that the leaching of divalent iron leads slowly to free oxides by hydrolysis and oxidation, exhibiting a different reduction behavior.

Hematite, the thermodynamically more stable iron compound in nature shows a typical TPR profile with a series of reduction steps. The first reduction process occurs below $570^{\circ} \mathrm{C}$ and it is associated to the formation of $\mathrm{Fe}_{3} \mathrm{O}_{4}$, according to equation:

$$
3 \mathrm{Fe}_{2} \mathrm{O}_{3}+\mathrm{H}_{2} \rightarrow 2 \mathrm{Fe}_{3} \mathrm{O}_{4}+\mathrm{H}_{2} \mathrm{O}
$$

At higher temperature magnetite is reduced to metallic iron: 


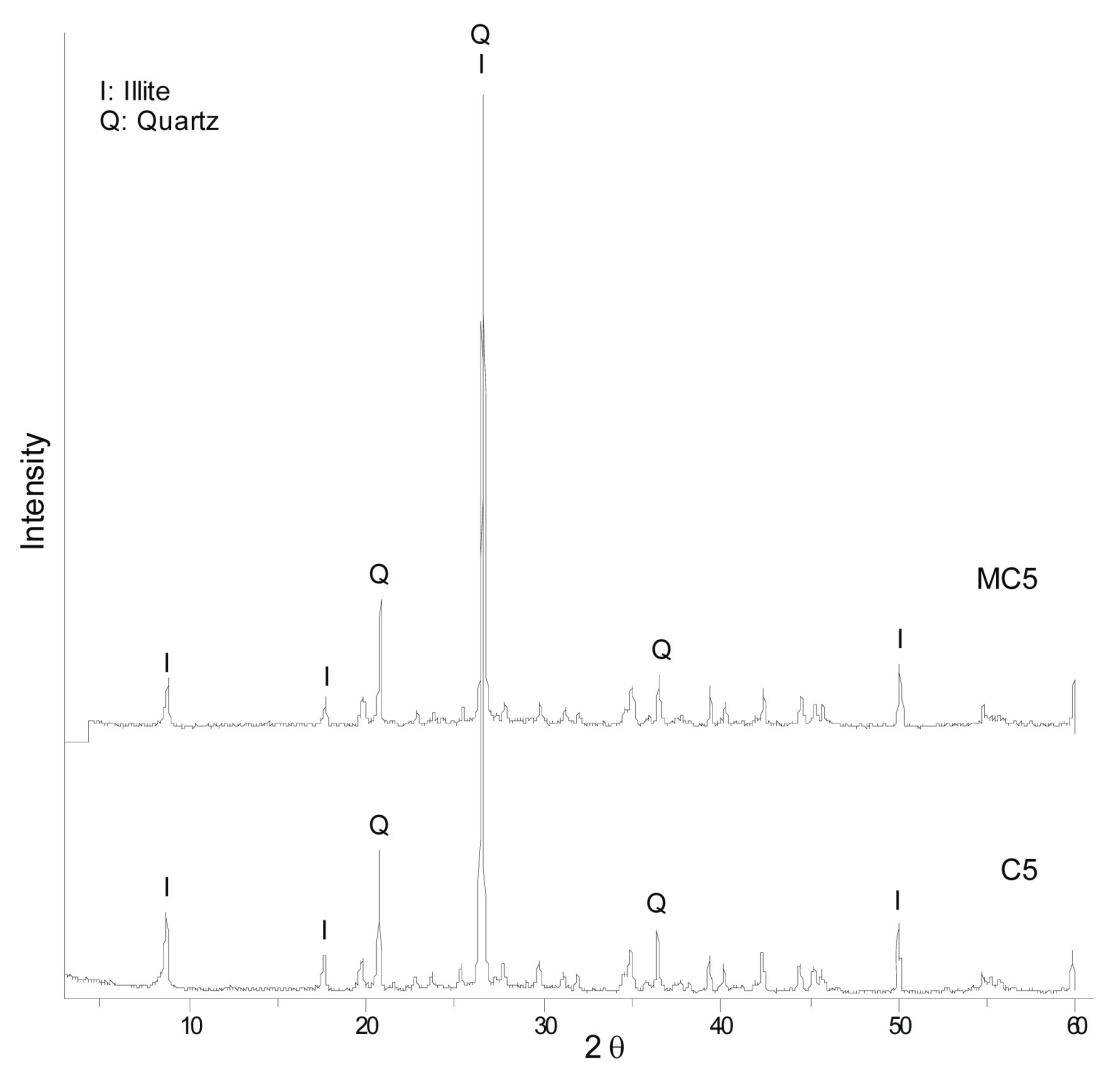

Figure 2. XRD patterns of C5 clay and its modified form (MC5).

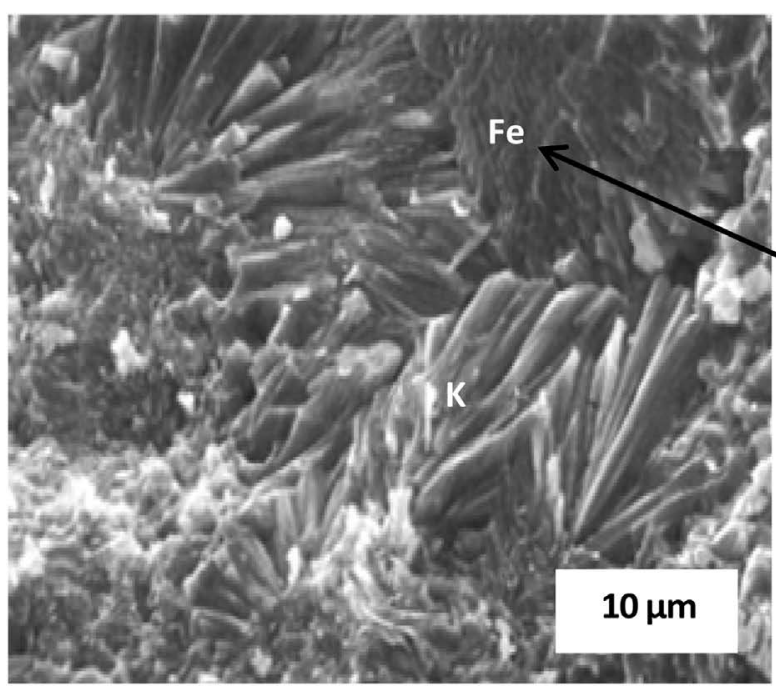

\section{$\mathrm{O}$}

Figure 3. SEM-EDS of C1 sample.

$$
2 \mathrm{Fe}_{3} \mathrm{O}_{4}+8 \mathrm{H}_{2} \rightarrow 6 \mathrm{Fe}+8 \mathrm{H}_{2} \mathrm{O}
$$

The step (2) may also follow a more complex reduction pathway through the $\mathrm{FeO}$ formation:

$2 \mathrm{Fe}_{3} \mathrm{O}_{4} \rightarrow 6 \mathrm{FeO} \rightarrow 6 \mathrm{Fe}$ [25] [26]. The $\mathrm{H}_{2}$ consumption in each step of the reduction process can be established from integrated areas of the corresponding TPR peaks. The theoretical value of electron exchanged to give $\mathrm{Fe}^{\circ}$ is equal to 3 and the hydrogen required for step (2) is 8 times larger than for step (1). 

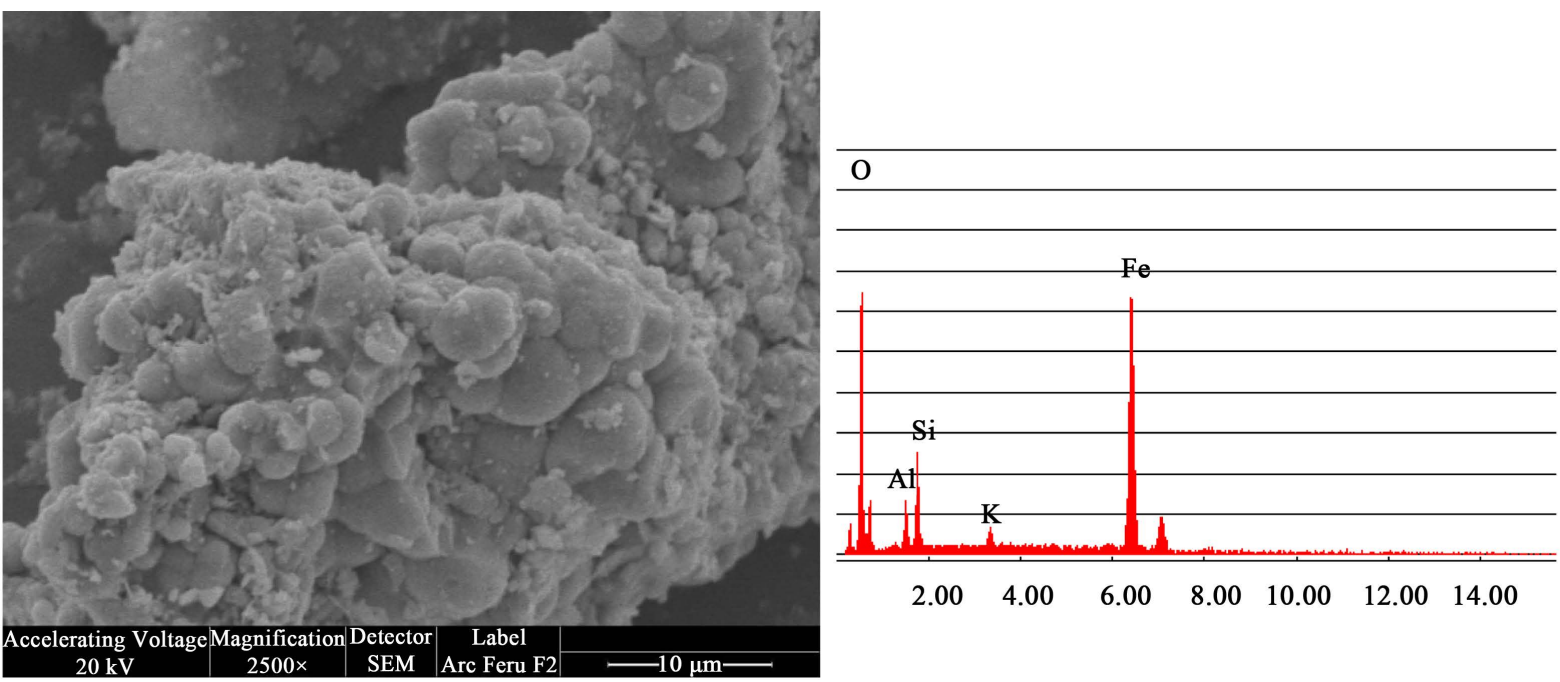

Figure 4. SEM-EDS of C4 sample with a heterogeneous distribution of iron.
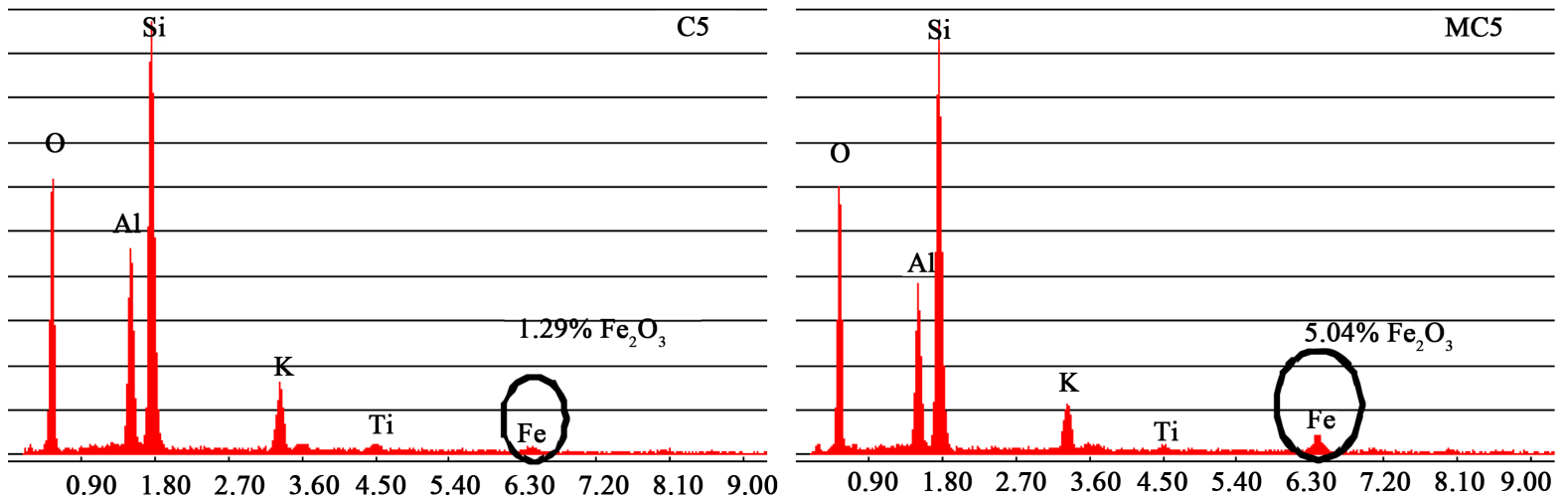

Figure 5. SEM-EDS of C5 and MC5 samples.

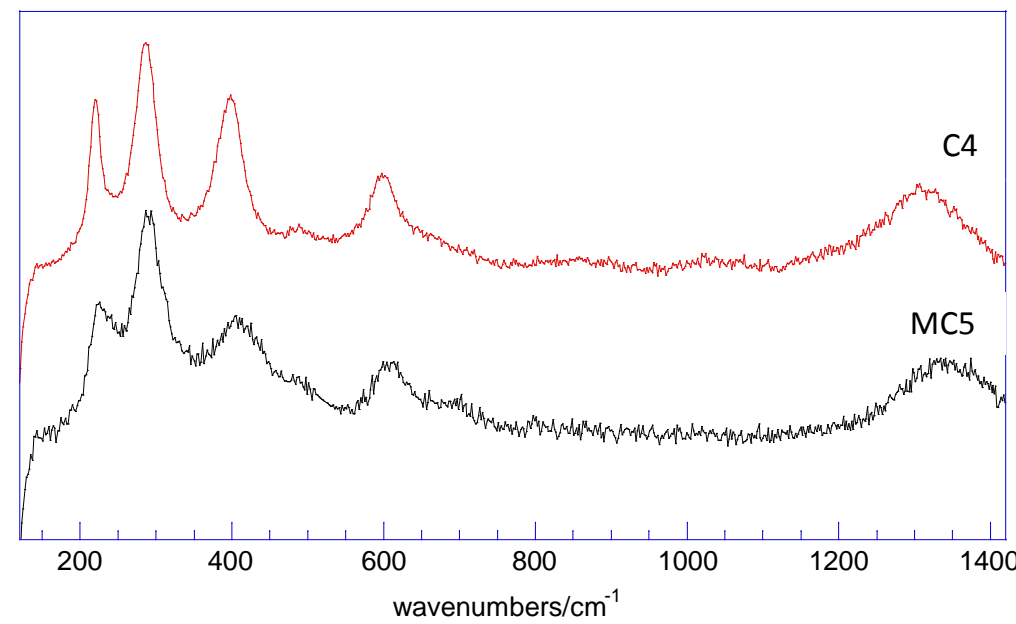

Figure 6. Micro-Raman spectra of C4 and MC5 samples.

Figure 7(a) shows TPR profiles of original clay samples. They were characterized by hydrogen consumption in the range $300^{\circ} \mathrm{C}-570^{\circ} \mathrm{C}$, assigned to the reduction step (1) and one or two intense peaks located above $570^{\circ} \mathrm{C}$, 

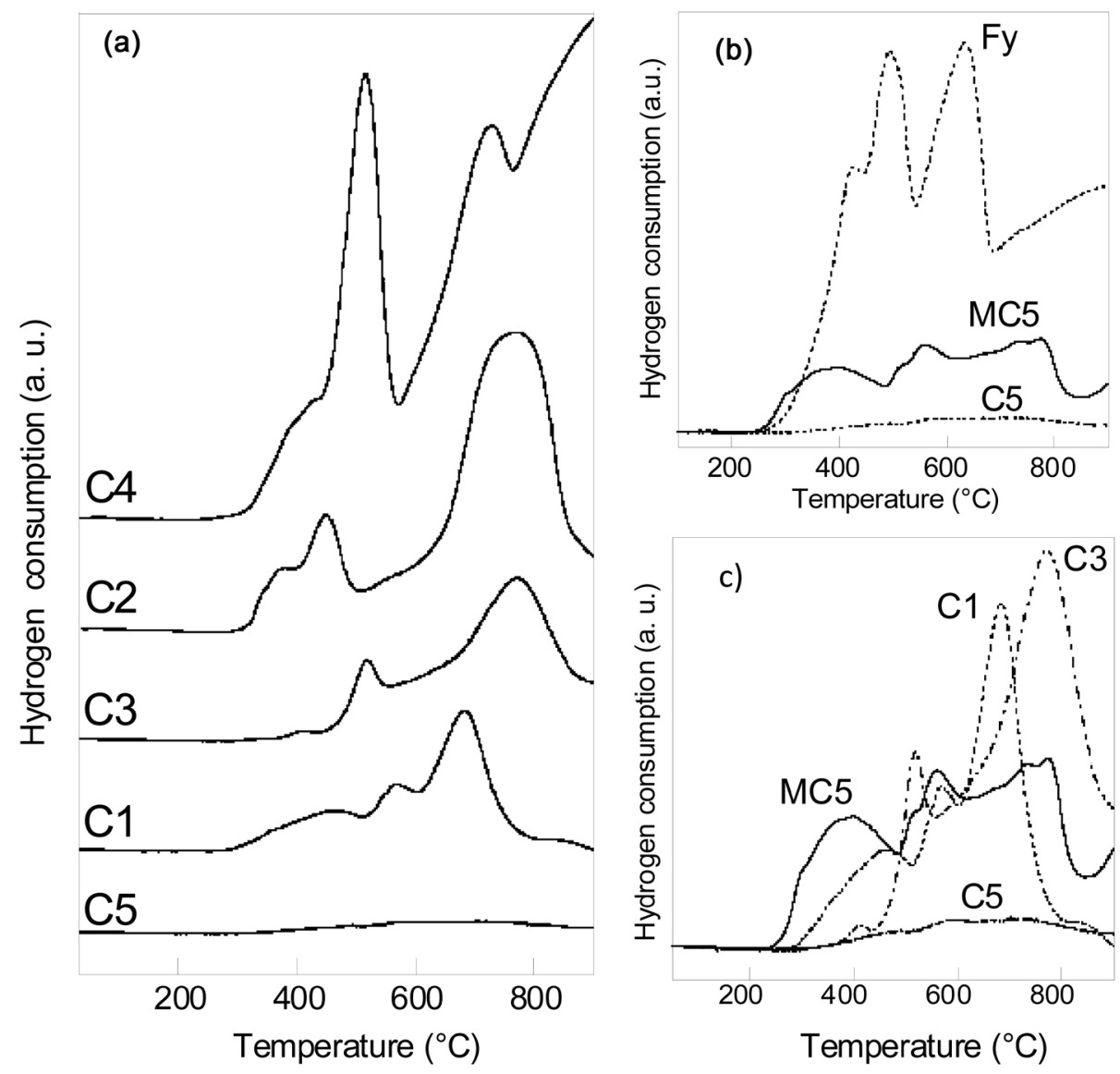

Figure 7. (a) TPR profiles of original clay samples; (b) Comparative TPR profiles of ferrihydrite (Fy), C5 and MC5; (c) Comparative reduction behavior of C1, C3, C5 and MC5 samples.

assigned to the two-step magnetite reduction sequence through $\mathrm{FeO}$ (step 2) depending on the structural stability of the clay. The first step of reduction shows the higher shifting of the peaks as well as the intensity variation for different samples. This can be related to structural differences regarding iron arrangement and crystallinity, facts that could be indicative of different adsorptive processes.

The iron reduction extent of all samples, after heating in $\mathrm{H}_{2}$ up to $900^{\circ} \mathrm{C}$, expressed as electrons consumed per iron atom (column 5) is given in Table 2. A e $\mathrm{e}^{-} / \mathrm{Fe}$ equal or close to 3 is indicative that before reduction all iron is present as $\mathrm{Fe}(\mathrm{III})$. Values lower than 3 suggest that a fraction of iron is not reduced to $\mathrm{Fe}^{\circ}$ or is originally present in a lower oxidation state. The area-ratio between high temperature peaks to low temperature peaks of samples was in the range 6.2 - 7.3. These values were close to 8 , value expected for the hydrogen consumption in the two reduction steps.

For $\mathrm{C} 1$ sample, peaks corresponding to the two reduction steps are overlapped and the iron reduction seems to be not complete or the original iron is not totally Fe(III), reaching the $\mathrm{e}^{-} / \mathrm{Fe}$ value of 2.27 . This sample, constituted by kaolinite, decomposes at $550^{\circ} \mathrm{C}$ with the lattice collapse, to form amorphous metakaolinite, fact that also affects the reduction behavior.

The TPR profile of C3 sample resembles that of hematite, the main iron phase revealed by XRD. TPR of C2 sample shows signals at temperature lower than that of C3, due to the presence of goethite [25]. The first intense peak observed for the $\mathrm{C} 4$ sample can be due to the high content of iron oxide phase (hematite). However, the goethite presence (not observed by XRD) must not be discarded because of the small TPR signal at lower temperature similarly to that observed for C2 sample. In relation to second reduction step, a progressive shift to higher temperature at increasing iron content is observed. This can be assigned to blocking effect of active sites by reduced Fe.

Structural characteristics of ferrihydrite ensure a great number of surface active sites, showing Fe linked to O, 
to $\mathrm{OH}$ groups and to $\mathrm{H}_{2} \mathrm{O}$ molecules. The presence of defects (stacking faults) and a distorted Fe octahedral coordination in a Kegging-like lattice have been reported [14]. These characteristics contribute to the $\mathrm{H}_{2}$ accessibility for the reduction. Figure 7(b) gives the comparative TPR profiles for ferrihydrite, C5 and MC5 samples. The very small reduction signal from $500^{\circ} \mathrm{C}$ for the $\mathrm{C} 5$ sample was affected by the chemical treatment revealing a reduction behavior similar to that observed for the nanoscopic ferrihydrite with the consequent increase of the total $\mathrm{e}^{-} / \mathrm{Fe}$.

Figure 7(c) shows the TPR signals of C5, MC5, C1 and C3 in order to compare reduction temperature shifts according to the iron species present in the clay mineral. So, the reducibility related to the first reduction step of iron was: ferrihydrite $>$ crystalline hydrous oxide (goethite) $>$ anhydrous oxide (hematite) $>$ clay structural iron.

Figure 8 shows TPR profiles of ferrihydrite and hematite that was obtained by temperature programmed oxidation (TPO) of reduced ferrihydrite. It is clearly apparent that the ferrihydrite reduction starts below $300^{\circ} \mathrm{C}$, about $100^{\circ} \mathrm{C}$ before hematite. The second reduction step occurs at similar temperature for both oxide species (about $660^{\circ} \mathrm{C}$ ).

The adsorption processes to remove arsenic from natural species (hematite, goethite, red mud, and other simple and complex iron oxides as well as minerals impregnated with iron salts, follow the Langmuir isotherm [5] [6] [11] [19] [21]. So, from the good fit for all studied samples according to the Langmuir model, it is possible to calculate the amount of As adsorbed at equilibrium expressed as $\mu \mathrm{g}$ of As retained per gram of mineral, as it is summarized in Table 3. C5 sample was not included in the table because As was not retained. The original As in this sample was leached, as it is observed in other poor-iron aluminosilicates [18].

It is clearly observed that the effectiveness of As adsorption is straightforwardly related not only to the iron content but also to structural characteristics of iron oxide systems dispersed on the clay surface. In this sense for

Table 2. Iron reduction extent in original and modified clay.

\begin{tabular}{ccccc}
\hline Sample & $\% \mathrm{Fe}_{2} \mathrm{O}_{3}$ & $\mathrm{Fe}$ content (mmol/g) & $\mathrm{H}_{2}$ consumption (mmol/g) & Total e/Fe \\
\hline $\mathrm{C} 1$ & 7.39 & 0.924 & 1.05 & 2.27 \\
$\mathrm{C} 2$ & 13.80 & 1.725 & 2.59 & 3.00 \\
$\mathrm{C} 3$ & 9.00 & 1.125 & 1.69 & 3.00 \\
$\mathrm{C} 4$ & 54.50 & 6.812 & 8.95 & 2.63 \\
$\mathrm{C} 5$ & 1.07 & 0.134 & 0.18 & 2.68 \\
$\mathrm{MC5}$ & 3.88 & 0.485 & 0.69 & 2.84 \\
\hline
\end{tabular}

Table 3. Effectiveness of As adsorption $\left(\mu \mathrm{g} \mathrm{As}^{-1}\right)$.

\begin{tabular}{cccccc}
\hline Sample & C1 & C2 & C3 & C4 \\
\hline Adsorbed As $\left(\mu \mathrm{g} \cdot \mathrm{g}_{\text {material }}{ }^{-1}\right)$ & 53.5 & 89.2 & 42.7 & 445.5 \\
\hline
\end{tabular}

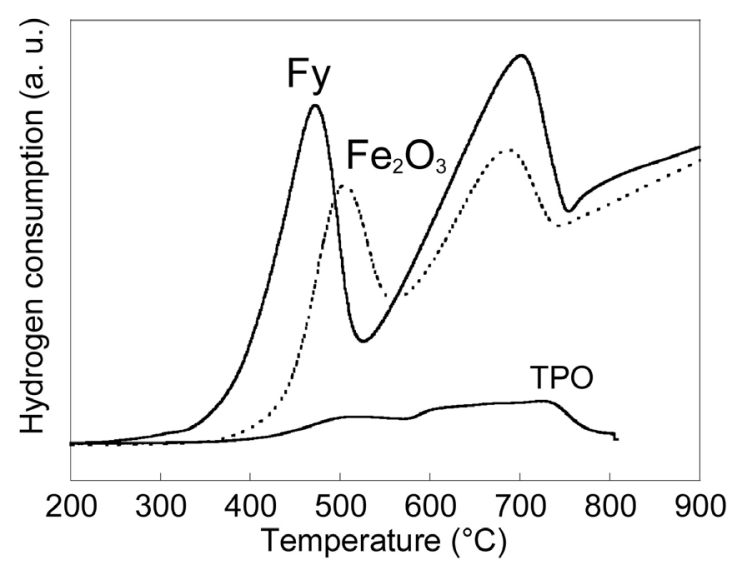

Figure 8. TPR profiles of ferrihydrite (FY) and hematite $\left(\mathrm{Fe}_{2} \mathrm{O}_{3}\right)$ obtained by oxidation of the reduced FY (TPO). 
comparable iron content values (C1 and C3 samples) the goethite content enhanced the As-adsorption respect to the close packed hematite. The behavior of $\mathrm{C} 2$ sample can be attributed to higher iron content and simultaneous presence of goethite and hematite. These results can be correlated with the availability of $\mathrm{H}_{2}$ to reach the iron active sites, which was revealed in TPR profiles. The best arsenic adsorption for C4 sample was due to high iron in the material composition.

In relation to MC5 sample, it was possible to observe that clay activation transformed a poor-iron clay in an efficient geomaterial to remove arsenic. In fact, the increase of iron content from $1.07 \%$ to $3.88 \%$ by chemical modification with $\mathrm{Fe}(\mathrm{III})$ solutions was enough to exceed the performances of natural samples containing between $7.39 \%$ and $13.80 \%$ of $\mathrm{Fe}_{2} \mathrm{O}_{3}$. Likewise, the arsenic removal was very efficient even in comparison with the C4 sample (containing the larger iron content). The effect of hydrous oxy-hydroxide iron deposited on the clay (small particle size, distorted iron structural environment and homogeneous distribution in surface) seems to be substantial factors for arsenate adsorption. In fact, the treatment with iron salts creates active sites for the arsenate $(\mathrm{V})$, interacting through the formation of inner-sphere bidentate or monodentate surface complexes [12].

\section{Conclusions}

The activation of poor-iron clay, by means of a simple chemical modification with Fe(III) solutions, transforms low-cost natural species in efficient geomaterials to remove arsenic, being an effective, accessible and ecofriendly technological alternative to solve a serious environmental problem.

The study of thermal reduction behavior of natural clay minerals containing iron, as well as of Fe(III) activated iron-poor species allowed establishing a correlation between iron reducibility and performances as Arsenic adsorbents. TPR technique resulted useful to analyze reactivity of natural and synthetic iron oxide arrangements in clay surface through accessibility of the $\mathrm{H}_{2}$ reducing agent. It has been found that the decrease of the iron reduction temperature was concomitant with the availability of active iron sites and consequently with a best arsenic adsorption.

This effect was observed through the first $\mathrm{Fe}(\mathrm{III})$ reduction step (below $570^{\circ} \mathrm{C}$ ), where the reducibility sequence was ferrihydrite $>$ hydrous oxide (goethite) $>$ anhydrous oxide (hematite) $>$ structural iron in clay. With respect to arsenic retention by means of diverse species of clay minerals with comparable iron amounts, the structural characteristics of dispersed oxides on the surface determine the magnitude of the process. Iron as goethite enhanced the arsenic adsorption in comparison with hematite, although it is also evident that the effect of very high iron content predominates over structural parameters of oxides. The increase of adsorption capability by chemical activation with iron salts can be attributed to ferrihydrite properties (particularly structure, size and surface), which allowed to reach an arsenic removal level comparable to that observed for a natural iron-rich sample.

\section{Acknowledgements}

The work was done by financial support of ANPCyT BID 2011 PICT-2186 Argentina.

\section{References}

[1] Mandal, B and Suzuki, K. (2002) Arsenic round the World: A Review. Talanta, 58, 201-235. http://dx.doi.org/10.1016/S0039-9140(02)00268-0

[2] Smedley, P. and Kinninburgh, D.G. (2002) A Review of the Source, Distribution and Behavior of Arsenic in Natural Waters. Applied Geochemistry, 17, 517-568. http://dx.doi.org/10.1016/S0883-2927(02)00018-5

[3] Bundschuh, J., Litter, M., Parvez, F., Román-Ross, G., Nicolli, H., Jean, J., Liu, J., López, D., Armienta, M., Guilherme, L., Gomez Cuevas, A., Cornejo, L., Cumbal, L. and Toujaguez, R. (2012) One Century of Arsenic Exposure in Latin America: A Review of History and Occurrence from 14 Countries. Science of the Total Environment, 429, 2-35. http://dx.doi.org/10.1016/j.scitotenv.2011.06.024

[4] Stollenwerk, K. (2003) Geochemical Processes Controlling Transport of Arsenic in Groundwater: A Review of Adsorption. In: Arsenic in Groundwater: Geochemistry and Occurrence, Chapter 3, 67-100. http://dx.doi.org/10.1007/0-306-47956-7_3

[5] Guo, H.; Stüben, D. and Berner, Z. (2007) Removal of Arsenic from Aqueous Solution by Natural Siderite and Hematite. Applied Geochemistry, 22, 1039-1051. http://dx.doi.org/10.1016/j.apgeochem.2007.01.004 
[6] Mamindy-Pajany, Y., Hurel, Ch., Marmier, N. and Roméo, M. (2009) Arsenic Adsorption onto Hematite and Goethite. Comptes Rendus Chimie, 12, 876-881. http://dx.doi.org/10.1016/j.crci.2008.10.012

[7] Bundschuh, J., Bhattacharya, P., Sracek, O., Mellano, M., Ramírez, A., Storniolo, A., Martín, R., Cortés, J., Litter, M. and Jean, J. (2011) Arsenic Removal from Groundwater of the Chaco-Pampean Plain (Argentina) Using Natural Geological Materials as Adsorbents. Journal of Environmental Science and Health Part A, 46, 1297-1310. http://dx.doi.org/10.1080/10934529.2011.598838

[8] Giles, D., Mohapatra, M., Issa, T., Anand, S. and Singh, P. (2011) Iron and Aluminium Based Adsorption Strategies for Removing Arsenic from Water. Journal of Environmental Management, 92, 3011-3022. http://dx.doi.org/10.1016/j.jenvman.2011.07.018

[9] Sarkar, S., Greenleaf, J.E., Gupta, A., Uy, D. and SenGupta, A.K. (2012) Sustainable Engineered Processes to Mitigate the Global Arsenic Crisis in Drinking Water: Challenges and Progress. Annual Review of Chemical and Biomolecular Engineering, 3, 497-517. http://dx.doi.org/10.1146/annurev-chembioeng-062011-081101

[10] Aredes, S., Klein, B. and Pawlik, M. (2012) The Removal of Arsenic from Water Using Natural Iron Oxide Minerals. Journal of Cleaner Production, 29-30, 208-213. http://dx.doi.org/10.1016/j.jclepro.2012.01.029

[11] Tabelin, C.B., Igarashi, T., Yoneda, T. and Tamamura, S. (2013) Utilization of Natural and Artificial Adsobents in the Mitigation of Arsenic Leached from Hydrothermal Alterated Rock. Engineering Geology, 156, 58-67. http://dx.doi.org/10.1016/j.enggeo.2013.02.001

[12] Haque, N., Morrison, G., Cano-Aguilera, I. and Gardea-Torresdey, J. (2008) Iron-Modified Light Expanded Clay Aggregates for the Removal of Arsenic (V) from Groundwater. Microchemical Journal, 88, 7-13. http://dx.doi.org/10.1016/j.microc.2007.08.004

[13] Cornell, R. and Schwertmann, U. (2003) The Iron Oxides. Structure, Properties, Reactions, Occurrences and Uses. 2nd, completely revised and extended Edition, Wiley-VCH, 664 p. http://dx.doi.org/10.1002/3527602097

[14] Michel, F., Ehm, L., Antao, S., Lee, P., Chupas, P., Liu, G., Strongin, D., Schoonen, M., Phillips, B. and Parise, J. (2007) The Structure of Ferrihydrite, a Nanocrystalline Material. Science, 316, 1726-1729. http://dx.doi.org/10.1126/science.1142525

[15] Chen, W., Parette, R., Zou, J., Cannon, F. and Dempsey, B. (2007) Arsenic Removal by Iron Modified Activated Carbon. Water Research, 41, 1851-1858. http://dx.doi.org/10.1016/j.watres.2007.01.052

[16] Maji, S.K, Kao, Y.H., Liao, P.Y., Lin, Y.J. and Liu, C.W. (2013) Implementation of the Adsorbent Iron-Oxide-Coated Natural Rock (IOCNR) on Synthetic As(III) and on Real Arsenic-Bearing Simple with Filter. Applied Surface Science, 284, 40-48. http://dx.doi.org/10.1016/j.apsusc.2013.06.154

[17] Churchman, G., Gates, W., Theng, B. and Yuan, G. (2006) Clays and Clay Minerals for Pollution Control. In: Bergaya, F., Theng, B.K.G. and Lagaly, G., Eds., Handbook of Clay Science: Developments in Clay Science, Vol. 1. Chapter 11.1, 625-675. http://dx.doi.org/10.1016/S1572-4352(05)01020-2

[18] Botto, I.L., González, M.J., Gazzolli, D. and Soto, E. (2013) Iron Activation of Natural Aluminosilicates to Remove Arsenic from Groundwater. Journal of Environmental Science and Engineering A, 2, 744-752.

[19] González, M.J., Botto, I.L, Canafoglia, M.E., Coccaro, L. and Soto, E. (2015) Iron-Modification of Pyroclastic Material from PCCVC Eruption (Chile): Characterization and Application to Remove Arsenic from Groundwater. Journal of Environmental Protection, 6, 1124-1133. http://dx.doi.org/10.4236/jep.2015.610099

[20] Schwertmann, U. and Cornell, R. (2000). Iron Oxides in the Laboratory: Preparation and Characterization. 2nd Edition, WILEY-VCH, Weinheim. http://dx.doi.org/10.1002/9783527613229

[21] Chen, R., Zhang, Z., Yang, Y., Lei, Z., Chen, N., Guo, X., Zhao, C. and Sugiura, N. (2011) Use of Ferric-Impregnated Volcanic Ash for Arsenate (V) Adsorption from Contaminated Water with Various Mineralization Degrees. Journal of Colloid and Interface Science, 353, 542-548. http://dx.doi.org/10.1016/j.jcis.2010.09.066

[22] Hanesch, M. (2009) Raman Spectroscopy of Iron Oxides and Oxy(hydroxides) at Lower Laser Power and Possible Application in Environmental Magnetic Studies. Geophysical Journal International, 177, 941-948. http://dx.doi.org/10.1111/j.1365-246X.2009.04122.x

[23] Das, S. and Hendry, M. (2011) Application of Raman Spectroscopy to Identify Iron Minerals Commonly Found in Mine Wastes. Chemical Geology, 290, 101-108. http://dx.doi.org/10.1016/j.chemgeo.2011.09.001

[24] Mazzetti, L. and Thistlethwaite, P.J. (2002) Raman Spectra and Thermal Transformations of Ferrihydrite and Schwertmanite. Journal Raman Spectroscopy, 33, 104-111. http://dx.doi.org/10.1002/jrs.830

[25] Jozwiak, W.K., Kaczmarek, E., Maniecki, T.P., Ignaczak, W. and Maniukiewicz, W. (2007) Reduction behavior of iron oxides in hydrogen and carbon monoxide atmospheres. Applied Catalysis A: General, 326, 17-27. http://dx.doi.org/10.1016/j.apcata.2007.03.021

[26] Pineau, A., Kanari, N. and Gaballah, I. (2006) Kinetics of Reduction of Iron Oxides by $\mathrm{H}_{2}$ : Part I: Low Temperature Reduction of Hematite. Thermochimica Acta, 447, 89-100. http://dx.doi.org/10.1016/j.tca.2005.10.004 